\title{
Os Arquivos Brasileiros de Ciências da Saúde adotam a metodologia SciELO
}

Ricardo Peres do Souto

Recentemente, os Arquivos Brasileiros de Ciências da Saúde assinaram convênio de cessão da Metodologia SciELO e, em breve, os artigos serão disponibilizados livremente no portal do NEPAS no formato eletrônico que já é familiar à comunidade científica brasileira e internacional. Espera-se que essa exposição ampliada permita maior visibilidade dos artigos dos ABCS, atraindo mais leitores, favorecendo mais citações e estimulando novas submissões. Esta é mais uma medida na direção de qualificar a revista, com o objetivo maior de solicitar indexação em novas bases de dados científicas.

Neste fascículo dos Arquivos Brasileiros de Ciências da Saúde:

- Malafaia e Rodrigues (p. 86) refletem sobre o processo de geração de um artigo científico e a qualidade do produto final, ressaltando algumas dificuldades adicionais encontradas por pesquisadores jovens;

- Fabra et al. (p. 89) estudam a contribuição de um Serviço de Dermatologia Cosmética para a melhoria da qualidade de vida e diminuição do sofrimento de pacientes em tratamento oncológico;

- Masuchi et al (p. 95) avaliam a importância do Terapeuta Ocupacional na equipe multiprofissional para oferta de assistência integral a idosos, promovendo melhor conservação da memória;

- Vanni et al. (p. 99) apresentam um saldo positivo para a técnica clássica do uso de retalho pediculado temporofrontal em cirurgia reparadora de cabeça e pescoço. Apesar de menos sofisticado, esse procedimento é bastante acessível e produz bons resultados;

- Bianco et al. (p. 103) discutem o possível papel de contaminantes ambientais na origem da endometriose, ressaltando a capacidade de interferência de algumas dessas substâncias sobre a ação e a sinalização de hormônios esteroides;

- Sanches et al. (p. 111) revisam o impacto da síndrome autoimune antifosfolípides como causa de abortos recorrentes, sugerindo a investigação dessa condição em pacientes com problemas de fertilidade;

- Speranzini et al. (p. 117) relatam caso pouco usual da transformação maligna de tecido de endometriose em adenocarcinoma endometrioide.

Finalizando, este fascículo ainda traz o programa e os resumos do $35^{\circ}$ Congresso Médico Universitário do ABC (COMUABC) que ocorrerá na Faculdade de Medicina do ABC, em Santo André (SP), de 16 a 21 de agosto de 2010.

Boa leitura. 